\title{
Potentials, Opportunities, and Challenges of Indonesian as an International (Scientific Journal) Language
}

\author{
Setya Yuwana Sudikan \\ \{setyayuwana@unesa.ac.id\}
}

Fakultas Bahasa dan Seni Universitas Negeri Surabaya, Indonesia

\begin{abstract}
The spread of the use of Indonesian language in other parts of the world is increasing. There are about 140 countries that teach Indonesian. It has potentials to be developed into a language of international scientific journals for it has numberless users that continue to grow in line with the growing interest of various international communities to learn Indonesian. Its ability to go hand in hand with the development of science and technology and become a medium for critical thinking, in addition to its grammatical simplicity, is an asset for Indonesian to improve its function as an international language (for scientific journal). The opportunity to become an international language (for scientific journal) is also open since there is no restriction on the number of international languages. Any language, including Indonesian, can become an international language if intralinguistic and extralinguistic factors support it. In this context, extralinguistic factors, especially those related to positive attitudes towards Indonesian language, are a challenge for which in the future the best solution needs to be found.
\end{abstract}

Keywords: Internationalization, Indonesian Language, International Scientific Journal

Potensi, Peluang, dan Tantangan Bahasa Indonesia sebagai Bahasa (Jurnal Ilmiah) Internasional

\begin{abstract}
Abstrak. Persebaran penggunaan bahasa Indonesia di belahan dunia semakin meningkat. Ada sekitar 140 negara yang mengajarkan bahasa Indonesia. BI memiliki potensi untuk dikembangkan menjadi bahasa jurnal ilmiah internasional karena memiliki pengguna yang banyak dan pengguna tersebut terus berkembang sejalan dengan pertumbuhan minat berbagai kalangan internasional untuk belajar BI. Kemampuannya untuk berjalan seiring dengan perkembangan ipteks dan menjadi pengungkap pikiran kritis, di samping kesederhanaan gramatika, menjadi modal bagi BI untuk meningkatkan fungsi sebagai Bahasa (jurnal ilmiah) internasional. Peluang untuk menjadi bahasa (jurnal ilmiah) internasional juga terbuka karena tidak ada pembatasan jumlah bahasa internasional. Bahasa apa pun, termasuk BI, dapat menjadi bahasa internasional bila faktor intralinguistik dan ekstralinguistik mendukung. Dalam konteks ini, faktor ekstralinguistik khususnya yang berkaitan dengan sikap positif terhadap BI menjadi tantangan tersendiri yang ke depan perlu dicarikan solusi terbaik.
\end{abstract}

Kata kunci: Internasionalisasi, Bahasa Indonesia, Jurnal Ilmiah Internasional

\section{Pendahuluan}

Kehadiran UU Nomor 24 Tahun 2009 tentang Bendera, Bahasa, dan Lambang Negara, serta Lagu Kebangsaan memberikan banyak insentif bagi bahasa Indonesia (BI), di antaranya 
BI berpotensi menjadi bahasa internasional. Potensi tersebut tampak eksplisit pada pasal 44, Bagian Keempat tentang Peningkatan Fungsi BI Menjadi Bahasa Internasional, Bab III tentang Bahasa Negara bahwa 1) pemerintah meningkatkan fungsi BI menjadi bahasa internasional secara bertahap, sistematis, dan berkelanjutan; 2) peningkatan fungsi BI menjadi bahasa internasional sebagaimana dimaksud pada ayat dikoordinasi oleh lembaga kebahasaan; dan 3) ketentuan lebih lanjut mengenai peningkatan fungsi BI menjadi bahasa internasional sebagaimana dimaksud pada ayat (1) diatur dalam peraturan pemerintah. Regulasi pemerintah tersebut secara yuridis formal memberikan landasan konstitusional dan membuka ruang yang luas bagi pengembangan BI sebagai bahasa internasional.

Bila regulasi pemerintah tersebut khususnya ayat 1) dicermati, ada tiga kata kunci dalam pengembangan BI menjadi bahasa Internasional, yaitu bertahap, sistematis, dan berkelanjutan. Ketiga kata kunci tersebut harus dijabarkan secara terperinci agar dapat diperoleh deskripsi kerja dan pemaknaan yang akurat. Perinciannya mencakup tahap-tahap apa yang akan dilakukan, apa tujuan dan sasaran per tahap, berapa lama waktu yang diperlukan untuk mencapai tujuan dan sasaran per tahap, program dan kegiatan apa yang akan dilakukan per tahap dan bagaimana penataan aspek teknisnya agar program dan kegiatan berjalan berkelanjutan, sarana dan prasarana apa yang harus dipersiapkan, berapa anggaran yang diperlukan untuk melaksanakan program dan kegiatan, dan bagaimana pemberdayaan lembaga kebahasaan untuk melaksanakan hal itu? Untuk merealisasikan hal tersebut, sejalan dengan pemikiran Wahya [1], pada satu sisi diperlukan rancangan pedoman pelaksanaan yang terarah dan sistematis dan pada sisi lain diperlukan kinerja maksimal para pelaksana yang cerdas, profesional, dan betul-betul memiliki semangat untuk meningkatkan fungsi BI sebagai Bahasa internasional demi kebesaran bangsa.

Peningkatan fungsi BI sebagai bahasa internasional bila dikaitkan dengan fakta lapangan bukan visi yang tidak realistis karena saat ini BI sudah mengglobal. Hal itu terbukti dari persebarannya di berbagai belahan dunia. Data terakhir menunjukkan bahwa saat ini BI dipelajari dan diajarkan pada lebih dari 140 negara, di antaranya Australia (The Australian National University, The University of Western, The University of Sydney, Deakin University, The University of Queensland, The University of Adelaide, Flinders University, Western Sydney University, University of New England, La Trobe University, Monash University, The University of Melbourne, dan sebagainya); Jepang (mata kuliah Bahasa Indonesia diajarkan di Tokyo University of Foreign Studies); Ukraina (Universitas Nasional Taras Shevchenko Kyiv); Vietnam (Universitas Hong Bang); RRC (Tianjin University dan sebagainya); Maroko (Universitas Mohammed V); Korea Selatan (Hankuk University of Foreign Studies); Inggris (School of Oriental and African Studies [SOA] University of London); Belanda (Leiden Universiteit); USA (Yale University, University of Washington di Seattle, University of Hawai at Manoa, dan sebagainya); dan Singapura (National University of Singapore [NUS] dan sebagainya). Di Australia, BI bahkan menjadi satu-satunya bahasa asing yang digemari masyarakat, mahasiswa, guru, dosen, dan pegawai. Masyarakat Australia kini aktif belajar BI. Fenomena itu mengisyaratkan bahwa BI memiliki potensi tinggi dalam mengatasi permasalahan kesiapan memasuki tataan kehidupan global, seperti perdagangan bebas dan teknologi informasi [2].

Dalam konteks internasional BI tidak hanya dipelajari di lingkungan pendidikan tinggi, tetapi juga digunakan untuk kepentingan komersial di media massa. Beberapa media massa elektronik, khususnya radio yang disiarkan secara internasional, misalnya BBC, Radio Australia, Suara Amerika (Voice of America/VoA), dan Radio Belanda secara rutin memunyai chanel siaran dalam bahasa Indonesia. Demikian pula fenomena penggunaan BI di internet. Banyak laman internet yang menyajikan berbagai informasi dengan menggunakan BI. Tidak 
tertinggal laman klub sepak bola ternama dunia yang untuk kepentingan bisnis dan kemajuan olahraga menyediakan layanan BI bagi penggemarnya.

\section{Hasil dan Pembahasan}

\subsection{Bahasa Internasional dan Bahasa Jurnal Ilmiah Internasional}

Terdapat banyak pendapat mengenai konsep bahasa internasional. Pei [3], misalnya, menyatakan bahwa bahasa internasional adalah bahasa yang digunakan untuk memfasilitasi komunikasi internasional. Contohnya adalah bahasa Inggris dan Perancis. Dengan menggunakan perspektif yang berbeda, Richard dkk. [4] menyatakan bahwa bahasa internasional adalah bahasa yang memiliki sebaran luas karena di samping dijadikan bahasa asing, juga digunakan sebagai bahasa kedua pada banyak negara. Bahasa yang demikian tidak hanya digunakan dalam konteks komunikasi sehari-hari, tetapi juga konteks khusus, misalnya jurnal ilmiah internasional.

Jurnal ilmiah internasional secara umum diklasifikasikan ke dalam dua kategori, yaitu 1) jurnal internasional dan 2) jurnal internasional bereputasi. Jurnal internasional berciri a) artikel ilmiahnya ditulis dalam bahasa resmi PBB (Inggris, Perancis, Cina, Arab, dan Spanyol), b) didistribusikan secara global dengan sistem electronic journal, c) editor board-nya berasal dari berbagai negara (minimal tiga negara), d) kontributor atau penulisnya berasal dari berbagai negara, dan e) terindeks pada salah satu lembaga pengindeks internasional, misalnya $D O A J, E B S C O$, atau Copernicus. Berbeda dengan jurnal internasional yang memiliki lima ciri tersebut, jurnal internasional bereputasi selain memenuhi persyaratan tersebut juga harus terindeks Scopus atau Clarivert Analytic (dulu dikenal dengan Thomson Reuters) dengan faktor dampak (impact factor) minimal 0,15.

Jurnal internasional bereputasi dapat diklasifikasikan menjadi beberapa kelas: kelas 1, kelas 2, dan kelas 3. Jurnal internasional bereputasi kelas 1 diterbitkan oleh penerbit terkenal (Elsevier, Springer, Blackwell), memiliki faktor dampak, dan diindeks oleh Scopus. Jurnal internasional bereputasi kelas 2 diterbitkan oleh bukan penerbit terkenal, memiliki faktor dampak, dan diindeks oleh Scopus. Jurnal internasional bereputasi kelas 3 diterbitkan oleh bukan penerbit terkenal, tidak memiliki faktor dampak, dan terindeks oleh Scopus. Dengan berdasar peringkat jurnal Scimago (Schimago journal rank/SJR), jurnal-jurnal yang terindeks Scopus tersebut dibagi menjadi empat kuartil (quartile yang kemudian disingkat menjadi Q), yakni Q-1 sampai dengan Q-4. Q-1 adalah kelompok jurnal yang memiliki nilai SJR paling tinggi dan Q-4 memiliki nilai SJR paling rendah [5].

Terkait dengan 1) gagasan peningkatan fungsi BI sebagai bahasa internasional yang diuraikan pada bagian "Pendahuluan" dan 2) fenomena penggunaan bahasa resmi $\mathrm{PBB} /$ Bahasa internasional dalam jurnal internasional, pada prinsipnya BI telah memenuhi syarat untuk merintis jalan sebagai bahasa internasional karena tidak terkendala ketika diposisikan sebagai media komunikasi ilmiah, sarana penalaran, dan media berpikir kritis. Dalam pertumbuhan dan perkembangan pesatnya khususnya dalam bidang kosakata dan peristilahan, BI dapat bersinergi dengan perkembangan teknologi informasi, ilmu pengetahuan, sosial-budaya, dan ekonomi.

Bila fakta penggunaan BI diamati, secara langsung atau tidak langsung BI terdampak oleh perkembangan ipteks dalam konteks global. Pada sisi lain, sifat BI yang terbuka dan fleksibel khususnya dalam mengakses kosakata peristilahan dalam bidang ipteks menyebabkan BI potensial menjadi bahasa modern. Kondisi yang demikian memungkinkan BI memerkaya 
konsep-konsep keilmuan baru yang sebelumnya tidak ada. Sejalan dengan pemikiran Sunaryo, BI sekaligus menjadi sarana berpikir kritis dan sarana pendukung pertumbuhan dan perkembangan ipteks yang hal itu sesuai pula dengan dinamika penggunaan bahasa internasional dalam jurnal internasional bereputasi.

\subsection{BI dan Situasi Kebahasaan di Kawasan Asia Tenggara}

Sepuluh negara anggota ASEAN masing-masing memiliki bahasa resmi negara. Brunei Darussalam memiliki bahasa resmi bahasa Melayu; Filipina bahasa Filipino; Indonesia BI; Kamboja bahasa Khmer; Laos bahasa Lao; Malaysia bahasa Melayu; Singapura bahasa China Mandarin, bahasa Melayu, Tamil, dan Inggris; Thailand bahasa Thai; dan Vietnam bahasa Vietnam. Keberagaman bahasa tersebut menimbulkan masalah komunikasi dan sejauh ini masalah tersebut diatasi dengan memilih bahasa Inggris sebagai bahasa pengantar dalam komunikasi antarpemimpin ASEAN. Akan tetapi, akhir-akhir ini mewacana gagasan bahwa penggunaan bahasa Inggris tidak menampakkan karakteristik ke-ASEAN-an. Karena itu, beberapa pihak mengusulkan BI sebagai bahasa ASEAN sebagai jembatan menuju bahasa internasional. Suhartono, sebagai contoh, menyatakan bahwa setidak-tidaknya terdapat empat argumen yang mendasari kelayakan BI untuk dipilih sebagai bahasa ASEAN, yaitu BI dipelajari pada banyak negara, mudah dikuasai, perkembangannya fantastis, dan sebagian kosakata BI juga terdapat dalam bahasa negara-negara ASEAN. Sebagai contoh, kata "candra" di Kamboja dan Indonesia sama-sama berarti "rembulan", "bhum" dan "kodang" di Thailand sama dengan "bumi" dan "gudang" dalam BI. Bila BI terpilih sebagai bahasa ASEAN, fenomena itu merupakan jembatan menuju bahasa internasional karena ASEAN berperan strategis dalam percaturan internasional. Percaturan internasional tidak berjalan optimal tanpa ASEAN. Maka, posisi BI sebagai bahasa ASEAN dengan sendirinya menjadi "komoditas" dan posisi tawar tersendiri bagi bangsa-bangsa lain untuk belajar BI dan pada gilirannya mengangkat BI sebagai bahasa internasional. Dalam hal ini, sejalan dengan pendapat Garvin dan Mathiot [6], secara kontinu diperlukan usaha-usaha yang berorientasi modernisasi atau intelektualisasi BI melalui 1) pengayaan kosakata dan peristilahan dan 2) peningkatan fungsi "menerjemahkan" kemampuan berpikir kritis penggunanya.

\subsection{Potensi BI sebagai Bahasa Ilmiah Internasional}

Terdapat dua faktor yang memengaruhi potensi BI dalam usaha menjadi bahasa internasional. Sejalan dengan pemikiran Philipson [7], kedua faktor tersebut adalah intrabahasa dan 2) ekstrabahasa. Faktor intrabahasa mencakup sistem BI yang telah mapan (telah memiliki sistem ejaan baku yang diatur dalam Pedoman Umum Ejaan Bahasa Indonesia dan Pedoman Umum Pembentukan Istilah) [8]. Faktor ekstrabahasa mencakup 1) sikap positif penutur BI yang ditandai dengan kesenangan orang Indonesia untuk menggunakan BI secara baik dan benar dan 2) kekayaan alam dan budaya Indonesia sehingga banyak pelaku ekonomi dari mancanegara berinvestasi di Indonesia. Hal itu berdampak pada jumlah orang asing yang belajar BI [8].

Terkait dengan faktor intrabahasa, potensi pengembangan BI terletak pada kemudahan memelajarinya. Hyun [9] menyatakan penggunaan aksara Latin dan tata bahasa yang sederhana merupakan dua hal dominan yang menjadi potensi pengembangan BI sebagai bahasa internasional. Digambarkannya bahwa bila orang mampu berbahasa Inggris, dia secara langsung dapat menggunakan BI. Akses untuk memelajari BI lebih mudah bila dibandingkan dengan, misalnya, bahasa Arab dan bahasa Vietnam yang memiliki aksara tersendiri. Tata bahasa BI mudah dipelajari karena tidak mengenal jenis kelamin, jumlah, kasus, waktu/kala, dan tingkat tutur (speech level). Pendapat yang sejalan lebih dulu dikemukakan oleh Atmazaki 
[10] bahwa struktur dan pembacaan BI tidak rumit sehingga memudahkan orang asing belajar BI.

Terkait dengan faktor ekstrabahasa, Atmazaki [10] menyatakan bahwa upaya menjadikan BI sebagai bahasa internasional dan peradaban dunia tidak hanya bergantung pada entitas bahasa tersebut. Sikap mental bangsa terjajah perlu diubah lebih dulu. Kebanggaan terhadap BI perlu ditumbuhkembangkan. Hal tersebut penting agar tidak "mengkhianati" usaha berbagai negara dalam mengajarkan BI di lembaga-lembaga pendidikan yang dimilikinya. Dengan kata lain, hal tersebut penting untuk mendukung usaha-usaha menjadikan BI penting bagi bangsa lain.

Sejalan dengan Philipson, Damhauser (2014) menyatakan terdapat empat syarat untuk menjadikan BI sebagai bahasa internasional, yaitu 1) BI harus digunakan dalam diplomasi dan perdagangan internasional, 2) BI harus berperan besar dalam penyebaran ilmu pengetahuan, 3) terdapat sistem sederhana dalam tata bunyi dan gramatikanya sehingga penutur asing mudah memelajarinya, dan 4) pemilik bahasa memiliki rasa percaya diri dan peduli terhadap BI. Dengan menggunakan perspektif yang lebih luas Sunendar (2019) menyatakan lima syarat yang harus dipenuhi agar BI dapat menjadi bahasa internasional, khususnya bahasa resmi PBB, yaitu 1) penuturnya banyak, 2) bahasanya mudah dimengerti dan dipahami, 3) negaranegara penggunanya banyak, 4) ekonomi dan politik negaranya stabil, dan 5) pemilik bahasa menggunakannya secara terus-menerus dan bangga menggunakannya pada ruang publik.

Persyaratan-persyaratan tersebut telah dipenuhi oleh BI. Pada 2009, misalnya, BI diposisikan secara resmi sebagai bahasa asing kedua oleh pemerintah daerah di Kota Ho Chi Minh di Vietnam. Menurut Kementerian Luar negeri, pada 2012 BI memiliki 4.463.950 penutur asli yang tersebar di luar negeri. Ketua DPR RI dalam sidang AIPA (ASEAN InterParliamentary Assembly) ke-32 pada tahun 2011 mengusulkan BI sebagai satu di antara bahasa kerja dalam sidang-sidang AIPA. Sesuai dengan kemajuan yang dicapai oleh bangsa Indonesia pada era global, peran Indonesia dalam interaksi internasional juga telah menjadikan BI sebagai bahasa yang dipandang sangat penting di masyarakat internasional [11].

BI telah dipelajari oleh lebih dari 45 negara dengan jumlah lembaga tidak kurang dari 130 buah yang terdiri atas perguruan tinggi, pusat-pusat kebudayaan asing, KBRI, dan lembagalembaga khusus [11]. BI telah diresmikan oleh pemerintah daerah Vietnam sebagai bahasa yang diprioritaskan selain bahasa Perancis, Jepang, dan Inggris. Hal itu tecermin dalam kenyataan bahwa posisi Indonesia makin penting terutama dalam konteks pemecahan masalah-masalah berbasis konflik politik di berbagai kawasan. Kenyataan itu, di samping kepentingan pengembangan bisnis, politik, pendidikan, dan seni budaya, menyebabkan banyak orang dari luar negeri tertarik dan ingin belajar BI sebagai sarana komunikasi. Australia bahkan telah menjadikan BI sebagai mata pelajaran yang diajarkan pada lebih dari 500 sekolah dan menempatkan BI pada peringkat keempat bahasa terpopuler [12]. Fenomena tersebut mengisyaratkan bahwa usaha-usaha serius untuk meningkatkan fungsi BI sebagai bahasa ilmiah internasional beralasan.

\subsection{Tantangan BI menjadi Bahasa (Jurnal) Internasional}

Tantangan pengembangan BI sebagai bahasa (jurnal) internasional dapat dipilah menjadi dua bagian, yaitu 1) internal kebahasaan (linguistik dan sosiolinguistik) dan 2) eksternal. Menurut Wahya [1], sebelum BI berfungsi sebagai alat komunikasi internasional, BI harus dikenal lebih dulu oleh masyarakat internasional. Fakta di lapangan menunjukkan bahwa BI telah dikenal oleh sebagian masyarakat internasional. Tantangan yang kemudian perlu disikapi adalah menjadikannya berfungsi sebagai bahasa komunikasi internasional antarbangsa. 
Dalam konteks tersebut [1] mengusulkan dua pendekatan: sosiolinguistik dan diplomasi. Pada pendekatan sosiolinguistik ditegaskan bahwa penggunaan BI oleh masyarakat harus dapat menyelesaikan persoalan sosial, misalnya meningkatkan peran sosial dan kesejahteraan penuturnya. Dalam hal ini harus ada jaminan sosial bahwa siapa pun yang dapat berbicara dalam BI akan mendapatkan jaminan sosial yang terkait dengan kedudukan, penghasilan, dan kesejahteraan.

Berbeda dengan pendekatan sosiolingustik, pada pendekatan diplomasi ditegaskan bahwa diplomasi merupakan media yang berperan signifikan dalam merealisasikan kepentingankepentingan nasional khususnya dalam konteks relasi antarnegara. Diplomasi juga merupakan media yang fundamental dalam perealisasian kepentingan nasional dalam konteks relasi dengan organisasi-organisasi internasional. Melalui diplomasi yang unggul Indonesia mampu mengonstruksi citra positif dalam pencapaian tujuan-tujuan yang ditargetkan [12].

Terkait dengan diplomasi tersebut Badan Pengembangan dan Pembinaan Bahasa telah memiliki lembaga bernama Pusat Pengembangan Strategi dan Diplomasi Kebahasaan (PPSDB). Badan tersebut memiliki tiga cakupan kerja. Pertama, pemodelan solusi konflik komunitas atau multibahasa. Fokus kerjanya adalah penggalian stereotipe komunitas tutur bahasa tertentu terhadap komunitas tutur bahasa lain, penggalian kesepadanan adaptasi bahasa atau sastra dengan adaptasi sosial pada komunitas multibahasa, uji coba penanggulangan potensi konflik di dalam laboratorium kebinekaan bahasa, penguatan identitas keindonesiaan komunitas di wilayah perbatasan melalui pengembangan model diplomasi kebahasaan atau kesastraan, penguatan tataan kehidupan kebinekaan dalam ketunggalikaan melalui pemanfaatan bukti-bukti relasi geneologi kebahasaan atau kesastraan, dan pengembangan layanan informasi kebinekaan dalam ketunggalikaan melalui bukti geneologi kebahasaan atau kesastraan sebagai bentuk diplomasi kebahasaan dalam mendukung proses integrasi bangsa. Kedua, penyebaran bahasa negara dan peningkatan fungsi BI menjadi bahasa internasional khususnya pada forum PBB dalam bentuk penguatan identitas keindonesiaan melalui penyebaran BI, fasilitasi penutur BI, pendampingan penerjemah multibahasa bagi pejabat pada forum internasional, pengajaran bahasa Indonesia bagi Penutur Asing (BIPA), pendirian pusat-pusat pembelajaran BI di luar negeri, pengiriman duta BI ke luar negeri, dan peningkatan kerjasama dengan lembaga kebahasaan pada tingkat internasional. Ketiga, peningkatan kompetensi berbahasa asing strategis dan penerjemah. Fokus kerjanya adalah pendidikan dan pelatihan kebahasaan, diplomasi bahasa, penerjemahan, juru bahasa, dan penerjemahan dokumen strategis, karya sastra, dan buku ipteks.

Pelaksanaan program kerja PPSDB diorientasikan untuk menyempurnakan programprogram sebelumnya dalam konteks pengembangan dan pembinaan bahasa sebagai sarana komunikasi dengan titik fokus 1) pengayaan daya ungkap BI sebagai bahasa resmi negara dan 2) penguatan kompetensi komunikasi ber-BI secara resmi bagi warganegara. Selain itu, diplomasi BI dapat digunakan untuk membuka ruang bagi bangsa-bangsa lain dalam mendalami produk budaya bangsa Indonesia. Secara terperinci diplomasi bahasa dilakukan untuk 1) memperkokoh kesatuan dan kesatuan bangsa, 2) membangkitkan nasionalisme keindonesian manusia Indonesia, 3) membuka akses perluasan bahasa baik ke dalam maupun ke luar, 4) mempertahankan jati diri bangsa Indonesia, 5) membangun keutuhan bangsa Indonesia dan mempererat persahabatan dengan bangsa-bangsa di dunia, dan 6) memperkokoh nilai-nilai budaya bangsa yang kuat dan bermartabat.

Dalam kaitannya dengan diplomasi kebahasaan, bidang perencanaan luar negeri juga telah melakukan berbagai terobosan untuk memperdekat BI dengan kalangan internasional, misalnya melalui program BIPA dan DRI (Darmasiswa Republik Indonesia) yang tersebar di 
berbagai perguruan tinggi di Indonesia. Melalui program tersebut didatangkan mahasiswa dari berbagai negara untuk belajar BI dan budaya Indonesia.

\section{Simpulan}

BI memiliki potensi untuk dikembangkan menjadi bahasa jurnal ilmiah internasional karena memiliki pengguna yang banyak dan pengguna tersebut terus berkembang sejalan dengan pertumbuhan minat berbagai kalangan internasional untuk belajar BI. Kemampuannya untuk berjalan seiring dengan perkembangan ipteks dan menjadi pengungkap pikiran kritis, di samping kesederhanaan gramatika, menjadi modal bagi BI untuk meningkatkan fungsi sebagai Bahasa (jurnal ilmiah) internasional.

Peluang untuk menjadi bahasa (jurnal ilmiah) internasional juga terbuka karena tidak ada pembatasan jumlah bahasa internasional. Bahasa apa pun, termasuk BI, dapat menjadi bahasa internasional bila faktor intralinguistik dan ekstralinguistik mendukung. Dalam konteks ini, faktor ekstralinguistik khususnya yang berkaitan dengan sikap positif terhadap BI menjadi tantangan tersendiri yang ke depan perlu dicarikan solusi terbaik.

\section{Referensi}

[1] Wahya. Peningkatan Status Bahasa Indonesia sebagai Bahasa Internasional: Sudah Lebih Mantapkah Perencanaan Bahasanya? Makalah Simposium Internasional Perencanaan Bahasa; 2-4 November 2010; Jakarta.

[2] Marsudi. Eksistensi Bahasa Indonesia sebagai Bahasa Persatuan. Jurnal Sosial Humaniora. 2008; 1(2): 172-184.

[3] Pei M. Glossary of Linguistics Terminology. New York: Columbia University Press; 1966.

[4] Richard J, dkk. Longman Dictionary of Applied Linguistics. Burt Mill: Longman; 1987.

[5] Muchlisin ZA. Kiat Menulis Artikel Ilmiah Jurnal Nasional dan Internasional. Banda Aceh: Syiah Kuala University Press; 2018.

[6] Garvin PI, Mathiot M. The Urbanization of the Guarani Language: A Problem in Language and Culture, in Readings in the Sociology of Language.

[7] Philipson R. Linguistic Imperalism. Oxford University Press; 2008.

[8] Handoko MP, dkk. Potensi Pengembangan Bahasa Indonesia menjadi bahasa Internasioan. Jurnal Bahasa Indonesia bagi Penutur Asing (JBIPA). 2019; 1: 22-29.

[9] Hyun PJ. Potensi dan Tantangan Bahasa Indonesia Menuju Bahasa Internasional. Jurnal Sosioteknologi. 2015; 1(14): 12-20.

[10] Atmazaki. Sudah Pantaskah Bahasa Indonesia Menyandang Predikat Bahasa Internasional? diunduh dari https://atmazaki.wordpress.com/ 2011/ 01/07/tantanganbahasa-indonesia-menjadi-bahasa-internasional-dan-peradaban-dunia. 2011.

[11] Kompas. BIPA, Tingkatkan Fungsi Bahasa Indonesia Menjadi Bahasa Internasional" diunduh dari http://edukasi.kompas.com/read/2013/10/23/1253102/BIPA. 2013.

[12] Darma AANA, dkk. Penggunaan Bahasa Indonesia sebagai Media Diplomasi antara Indonesia dengan Thailand melalui Program Pengajaran Bahasa Indonesia untuk Penutur Asing (BIPA) pada Tahun 2011-2015. 
[13] Masraeng R. Diplomasi Bahasa Menjembatani Keragaman Bahasa Daerah dan Pengutamaan Bahasa Indonesia. Retorika: Jurnal Ilmu Bahasa. 2015; 1(1): 155-167. 